\title{
Article
}

\section{Magnicamarosporium diospyricola sp. nov. (Sulcatisporaceae) from Thailand}

\section{Phukhamsakda $\mathrm{C}^{1,2}$, Bhat $\mathrm{DJ}^{3}$, Hongsanan $\mathrm{S}^{1,2}$, Tibpromma $\mathrm{S}^{1,2}$, Yang $\mathrm{JB}^{4}$ and Promputtha $\mathbf{I}^{*}$}

${ }^{1}$ Key Laboratory for Plant Diversity and Biogeography of East Asia, Kunming Institute of Botany, Chinese Academy of Science, Kunming 650201, Yunnan, China

${ }^{2}$ Center of Excellence in Fungal Research, Mae Fah Luang University, Chiang Rai 57100, Thailand

${ }^{3}$ Formerly Department of Botany, Goa University, Goa, India; No. 128/1-J, Azad Housing Society, Curca, Goa Velha, India

${ }^{4}$ Germplasm Bank of Wild Species, Kunming Institute of Botany, Chinese Academy of Science, Kunming 650201, Yunnan, China

${ }^{5}$ Department of Biology, Faculty of Science, Chiang Mai University, Chiang Mai, Thailand

Phukhamsakda C, Bhat DJ, Hongsanan S, Tibpromma S, Yang JB, Promputtha I 2017 Magnicamarosporium diospyricola sp. nov. (Sulcatisporaceae) from Thailand. Mycosphere 8(4), 512-520, Doi 10.5943/mycosphere/8/4/3

\begin{abstract}
A new species of Magnicamarosporium, M. diospyricola was found on dead or dying twigs of a dicotyledonous plant in southern Thailand. The new species is distinct from other species in Sulcatisporaceae, as it has dematiaceous dictyosporous conidia. It differs from Magnicamarosporium iriomotense in its smaller conidiomata and conidia. Bayesian inference and maximum likelihood analysis of combined LSU, SSU, ITS, and TEF1- $\alpha$ sequence data indicate that $M$. diospyricola is a well-resolved species, sister to M. iriomotense, in the family Sulcatisporaceae. The morphology and phylogenetic placement of the new species are discussed in this paper.
\end{abstract}

Keywords - asexual morph - coelomycetes - Massarineae - Pleosporales - saprobes

\section{Introduction}

Camarosporium-like species account for a well-defined coelomycetous group characterized by dictyosporous conidia (Schulzer 1870, Sutton 1980). Based on molecular data, the type species of Camarosporium, C. quaternatum, is placed in the suborder Pleosporinae (Pleosporales) (Saccardo 1883, Crous et al. 2006, Wijayawardene et al. 2014a, b, Liu et al. 2015). Wijayawardene et al. (2016) illustrated brown-spored coelomycetes, including various Camarosporium-like taxa. Several authors have attempted to establish the phylogenic placement of Camarosporium-like taxa (Wijayawardene et al. 2014b, Liu et al. 2015). The Camarosporium-like taxa are presently shown to be polyphyletic.

Tanaka et al. (2015) illustrated the suborder Massarineae and described Magnicamarosporium based on Diplospora dubia (Rubiaceae). The genus is typified by $M$. iriomotense Tanaka \& Hirayama and shares a similar morphology with Camarosporium in its muriform, brown conidia. Nevertheless, molecular data shows that it belongs to Sulcatisporaceae. The genus is characterized by pycnidial conidiomata, with ellipsoid, subglobose, and muriform conidia (Crous et al. 2014, Tanaka et al. 2015). 
In this study, analysis of concatenated rDNA and TEF1- $\alpha$ sequence data using maximumlikelihood and Bayesian posterior probabilities, clearly showed that our strain clusters with Magnicamarosporium. Therefore, we introduce Magnicamarosporium diospyricola sp. nov. isolated from Diospyros malabarica in Thailand, based on both morphology and phylogenic analysis.

\section{Material \& Methods}

\section{Sample collection, morphological study and isolation}

Fresh specimens were collected from fallen twigs of Diospyros malabarica (Ebenaceae) in Krabi, Thailand, during 2015 and brought to the laboratory in plastic ziplock bags. Pure cultures were established from single ascospores on malt extract agar following the method of Chomnunti et al. (2014). Cultures were incubated at $25^{\circ} \mathrm{C}$ for up to 8 weeks. Type specimens were deposited in Mae Fah Luang University (MFLU) herbarium. Ex-type living cultures were deposited at the Mae Fah Luang Culture Collection (MFLUCC), and also deposited at the International Collection of Microorganisms from Plants (ICMP). Fungal slides were examined under a Nikon ECLIPSE 80i compound microscope and photographed with a Canon 600D digital camera fitted to the microscope. Measurements were made using Tarosoft (R) Image Frame Work program and photoplates using Adobe Photoshop CS6 Extended version 10.0 software (Adobe Systems, United States). Faces of fungi numbers and Index Fungorum numbers are provided (Jayasiri et al. 2015, Index Fungorum 2016).

\section{DNA extraction, amplification and sequencing}

DNA was extracted from mycelium with Biospin Fungus Genomic DNA Extraction Kit (BioFlux ${ }^{\circledR}$ ) (Hangzhou, P. R. China), following the manufacturer's protocol. Primer sequences are available at the WASABI database at the AFTOL website (aftol.org). Amplification reactions for LSU, SSU and ITS were performed according to Phukhamsakda et al. (2015). The PCR thermal cycle program for EF1-983F and EF1-2218R (Carbone \& Kohn 1999) for translation elongation factor 1-alpha (TEF1- $\alpha$ ) was set for denaturation at $96^{\circ} \mathrm{C}$ for 2 minutes, followed by 40 cycles of denaturation at $96^{\circ} \mathrm{C}$ for 45 seconds, annealing at $52^{\circ} \mathrm{C}$ for 30 seconds and extension at $72^{\circ} \mathrm{C}$ for 1.30 minutes, with a final extension step at $72^{\circ} \mathrm{C}$ for 5 minutes. DNA extracted and PCR proliferation products were checked on 1\% Agarose gel, the purified PCR products and the sequencing were performed by Shanghai Sangon Biological Engineering Technology \& Services Co. (Shanghai, P.R. China).

\section{Sequence alignment and phylogenetic analysis}

SeqMan v. 7.0.0 (DNASTAR, Madison, WI) was used to assemble consensus sequences. Sequences of closely related strains were retrieved using BLAST searches against GenBank (Benson et al. 2013). We also followed the strains from Tanaka et al. (2015) and these are listed in Table 1. Sequences were aligned with MUSCLE in MEGA 7 (Tamura et al. 2013) and MAFFT online tool version 7 (Katoh \& Standley 2013). The alignments were checked visually and improved manually wherever obligate nucleotides are necessary. Leading or trailing gaps exceeded from primer binding site were trimmed prior to tree building. Phylogenetic analyses were performed with the CIPRES webportal for maximum likelihood (ML) analysis (Miller et al. 2010) comparing with RAxML (O'meara et al. 2006) maximum likelihood analyses (ML), including 1,000 bootstrap replicates, as implemented in raxmlGUI version v.1.3.1 (Silvestro \& Michalak 2011). MrBayes v. 3.2.2 was performed for Bayesian analysis (Huelsenbeck \& Ronquist 2001). The search strategy was set to rapid bootstrapping. Analysis was carried out with the general time reversible (GTR) model for nucleotide substitution and a discrete gamma-distributed with invariable sites (GTRGAMMA+I) (Stamatakis et al. 2008, Guindon et al. 2010). The bootstrap replicates were summarized on to the best scoring tree. Maximum likelihood bootstrap values equal or greater than $50 \%$ are given in black below or above each node (Fig. 1). 
Table 1 Culture collection code and accession numbers used in this study.

\begin{tabular}{|c|c|c|c|c|c|}
\hline \multirow{2}{*}{ Taxon } & \multirow{2}{*}{ Strain number } & \multicolumn{4}{|c|}{ GenBank accession numbers } \\
\hline & & LSU & SSU & ITS & TEF1- $\alpha$ \\
\hline Bambusicola bambusae & MFLUCC 11-0614 & JX442035 & JX442039 & NR_121546 & - \\
\hline Bambusicola massarinia & MFLUCC 11-0389 & JX442037 & JX442041 & NR_121548 & - \\
\hline Bambusicola pustulata & MFLUCC 15-0190 & KU863107 & KU872112 & KU940118 & KU940190 \\
\hline Bambusicola splendida & MFLUCC 11-0439 & JX442038 & JX442042 & NR_121549 & - \\
\hline Bambusicola triseptatispora & MFLUCC 11-0166 & KU863109 & - & KU940120 & - \\
\hline Bambusistroma didymosporum & MFLUCC $13-0862^{\mathrm{T}}$ & KP761730 & KP761737 & KP761734 & KP761727 \\
\hline Camarographium koreanum & CBS $117159^{\mathrm{T}}$ & JQ044451 & - & JQ044432 & - \\
\hline Camarosporium aloes & CPC 21572 & KF777198 & - & KF777142 & - \\
\hline Camarosporium quaternatum & CBS 483.95 & GU301806 & GU296141 & - & GU349044 \\
\hline Deniquelata barringtoniae & MFLUCC $11-0422^{\mathrm{T}}$ & NG_042696 & JX254656 & NR_111779 & - \\
\hline Dictyosporium digitatum & JCM 19404 & $\mathrm{AB} 807515$ & - & LC014545 & AB808491 \\
\hline Dictyosporium elegans & NBRC $32502^{\mathrm{T}}$ & DQ018100 & DQ018079 & DQ018087 & - \\
\hline Dictyosporium thailandicum & MFLUCC 13-0773 & KP716707 & - & KP716706 & - \\
\hline Didymosphaeria rubi-ulmifolii & MFLUCC 14-0024 & KJ436585 & KJ436587 & - & - \\
\hline Keissleriella cladophila & CBS 104.55 & GU301822 & GU296155 & - & GU349043 \\
\hline Latorua caligans & CBS $576.65^{\mathrm{T}}$ & KR873266 & - & NR_132923 & - \\
\hline Latorua grootfonteinensis & CBS 369.72 & KR873267 & - & - & - \\
\hline Lentithecium fluviatile & CBS $122367^{\mathrm{T}}$ & GU301825 & GU296158 & - & GU349074 \\
\hline Lentithecium lineare & IFRD 2008 & FJ795435 & FJ795478 & - & - \\
\hline Macrodiplodiopsis desmazieri & CBS 221.37 & JX681100 & - & KR873236 & - \\
\hline Macrodiplodiopsis desmazieri & CPC 24971 & KR873272 & - & KR873240 & - \\
\hline Magnicamarosporium iriomotense & KT $2822^{\mathrm{T}}$ & AB807509 & AB797219 & AB809640 & AB808485 \\
\hline Magnicamarosporium diospyricola & MFLUCC 16-0419 & KY554212 & KY554211 & KY554210 & KY554209 \\
\hline Massarina eburnea & CBS 473.64 & GU301840 & GU296170 & - & GU349040 \\
\hline Montagnula aloes & CPC 19671 & JX069847 & - & JX069863 & - \\
\hline Murilentithecium clematidis & MFLUCC $14-0561^{\mathrm{T}}$ & KM408758 & KM408760 & KM408756 & KM454444 \\
\hline Neobambusicola strelitziae & CBS $138869^{\mathrm{T}}$ & KP004495 & - & KP004467 & - \\
\hline Neokalmusia brevispora & CBS $120248^{\mathrm{T}}$ & AB524600 & AB524459 & - & AB539112 \\
\hline Neottiosporina paspali & CBS 331.37 & EU754172 & EU754073 & KP170653 & GU349079 \\
\hline Palmiascoma gregariascomum & MFLUCC 11-0175 & KP744495 & KP753958 & KP744452 & - \\
\hline Paracamarosporium psoraleae & CPC $21632^{\mathrm{T}}$ & KF777199 & - & KF777143 & - \\
\hline Periconia homothallica & CBS 139698 & AB807565 & AB797275 & AB809645 & AB808541 \\
\hline Periconia pseudodigitata & CBS 139699 & AB807564 & AB797274 & LC014591 & AB808540 \\
\hline Phragmocamarosporium hederae & MFLUCC 13-0552 & KP842916 & KP842919 & - & - \\
\hline Phragmocamarosporium platani & MFLUCC 14-1191 ${ }^{\mathrm{T}}$ & KP842915 & KP842918 & - & - \\
\hline Pseudocamarosporium lonicerae & MFLUCC 13-0532 & KJ813278 & KJ819947 & KJ747047 & - \\
\hline Pseudocamarosporium propinquит & MFLUCC 13-0544 & KJ813280 & KJ819949 & KJ747049 & - \\
\hline Pseudocamarosporium tilicola & MFLUCC 14-0093 & KJ813281 & KJ819950 & KJ747050 & - \\
\hline Pseudochaetosphaeronema larense & CBS 639.94 & KF015610 & KF015651 & KF015655 & KF015683 \\
\hline Pseudochaetosphaeronema larense & CBS $640.73^{\mathrm{T}}$ & KF015611 & KF015652 & NR_132038 & KF015684 \\
\hline Stagonospora pseudocaricis & CBS 135132 & KF251762 & - & KF251259 & KF253209 \\
\hline Sulcatispora acerina & KT $2982^{\mathrm{T}}$ & LC014610 & LC014605 & LC014597 & LC014615 \\
\hline Sulcatispora berchemiae & KT 1607 & AB807534 & AB797244 & AB809635 & AB808509 \\
\hline Suttonomyces clematidis & MFLUCC 14-0240 ${ }^{\mathrm{T}}$ & KP842917 & KP842920 & - & - \\
\hline Xenocamarosporium acaciae & $\mathrm{CPC} 24755^{\mathrm{T}}$ & KR476759 & - & KR476724 & - \\
\hline
\end{tabular}

Type species from ex-type of each genus indicated with (T), new generated sequences in this study indicated in bold.

The model of evolution for the Bayesian inference analysis was determined with MrModeltest 2.3 (Nylander 2004) and the GTR $+\mathrm{I}+\mathrm{G}$ nucleotide substitution model was used for each partition based on the results from MrModeltest. Posterior probabilities (PP) (Rannala \& Yang 1996, Zhaxybayeva \& Gogarten 2002) were determined by Markov Chain Monte Carlo sampling (MCMC) in MrBayes v. 3.2.2 (Huelsenbeck \& Ronquist 2001). Six simultaneous Markov chains were run for $1,000,000$ generations and trees were sampled every $100^{\text {th }}$ generation. 10,000 trees were obtained. The suitable burn-in phase was determined by traces inspected in Tracer version 1.6 (Rambaut et al. 2014). Based on the tracer analysis, the first 1,000 trees representing $10 \%$ of burnin phase of the analyses were discarded. The remaining trees were used for calculating posterior probabilities in the majority rule consensus tree (critical value for the topological convergence 
diagnostic set to $\leq 0.01$ ). Bayesian Posterior Probabilities (PP) equal or greater than 0.90 are given above each node (Fig. 1).

Phylogenetic trees and data files were visualized in FigTree v. 1.4 (Rambaut \& Drummond 2008). The phylograms with bootstrap values and posterior probabilities on the branches are presented in Fig. 1, using graphical options available in Adobe Illustrator CS v. 6. All sequences generated in this study were submitted to GenBank. The finalized alignment and tree were deposited in TreeBASE, submission ID: 20569 (Piel et al. 1999).

\section{Results}

\section{Topology of phylogenetic analysis}

Partial nucleotides of LSU, SSU, ITS and TEF1- $\alpha$ dataset comprising 43 strains from the suborder Massarineae were used to determine the placement of Magnicamarosporium diospyricola. Camarosporium quaternatum (CBS 483.95) and C. aloes (CPC 21572) were used as the outgroup taxon (Fig. 1). The individual datasets were initially performed and compares the similarity of the placement topology. Overall topology was consistent (data not shown), therefore the alignments were combined and the results from phylogenetic analyses are given in Fig. 1.

The best scoring tree presented in Fig. 1, with a final likelihood value of In: -17532.41 . Magnicamarosporium diospyricola clustered in the Sulcatisporaceae. The strains cluster with strong support with $M$. iriomotense (95\% ML/1.00PP) and separated from other members in the family. Magnicamarosporium formed a sister clade and resided with Sulcatispora berchemiae (KT 1607), S. acerina (KT 2982), and Neobambusicola strelitziae (CBS 138869) and another genus in Sulcatisporaceae with significant support (100\%ML/1.00 PP).

\section{Taxonomy}

Magnicamarosporium diospyricola Phukhams, sp. nov.

Index Fungorum number: IF552777; Facesoffungi number: FoF 02897

Fig. 2

Etymology - The species habitat in reference of host

Holotype - MFLU 17-0001

Saprobic on dead twigs of Diospyros malabarica (Desr.) Kostel. Sexual morph Undetermined. Asexual morph Conidiomata 277-301 $\mu \mathrm{m}$ high $\times 289-337 \mu \mathrm{m}$ diam. protruding, partly immersed in the host, subglobose to depressed globose, uniloculate, dark brown to black, with a centrally located ostiole. Ostioles $129-145 \mu \mathrm{m}$ high $\times 74-116 \mu \mathrm{m}$ diam. $(\bar{x}=135 \times 96 \mu \mathrm{m}, \mathrm{n}$ = 5), central, oblong, thick-walled, periphysate, dark brown. Pycnidial wall 10-29 $\mu \mathrm{m}(-36 \mu \mathrm{m}$ at base corner) wide, composed of 7-9 layers of brown to dark brown cells; outer layers with textura globose to textura angularis cells; inner layers with hyaline cells bearing conidiogenous cells. Paraphyses 29-63 $\mu \mathrm{m}$ high $\times 2-4 \mu \mathrm{m}$ diam. $(\bar{x}=43 \times 3 \mu \mathrm{m}, \mathrm{n}=30)$, branched, regularly 1-2septate, hyaline. Conidiophores reduced to conidiogenous cells with one supporting cell. Conidiogenous cells 5-10 $\times 3-5 \mu \mathrm{m},(\bar{x}=8 \times 4 \mu \mathrm{m}, \mathrm{n}=20)$, holoblastic to annelidic, indeterminate, integrated, cylindrical, hyaline, smooth, with 1-2 prominent annellations. Conidia 24-35 × 14-21 $\mu \mathrm{m}(\bar{x}=30 \times 17 \mu \mathrm{m}, \mathrm{n}=50)$, obovoid to broadly oblong, sometimes pyriform, obtuse at apex, slightly tapered at base, with a circular basal scars, euseptate, with 5-7 transverse and 1-2 vertical septa, slightly constricted at median septa, hyaline when young, dark brown at maturity, smooth without a gelatinous sheath.

Culture characteristics - Colonies on MEA, reaching $40 \mathrm{~mm}$ diam. after 4 weeks at $25^{\circ} \mathrm{C}$, colonies dark-brown to black, dense, irregular, umbonate, with rough surface, strongly irregular at margin covering with white mycelium; reverse white at edges, dark brown to black at the center, radiating, irregular, margin rough, with orange pigment diffused to the agar. 


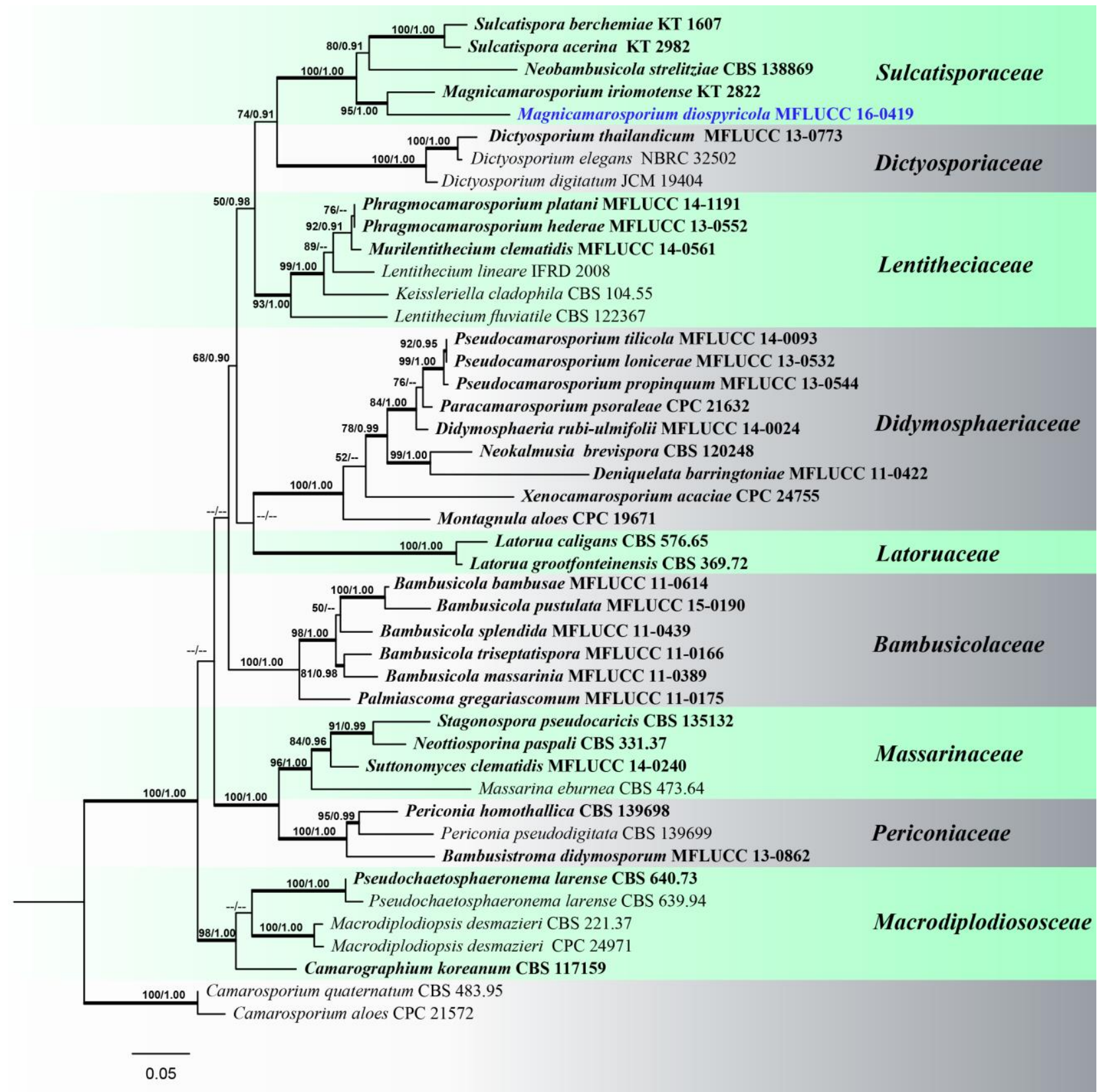

Figure 1 - The best scoring RAxML tree based on a combined partial LSU, SSU, ITS and TEF1- $\alpha$ gene datasets. Bootstrap values $\geq 50 \%$ from the maximum likelihood (ML) analysis are followed by Bayesian posterior probabilities (PP) values $\geq 0.90$. The tree is rooted with Camarosporium sensu stricto. The species determine in this study indicated in blue. The ex-type and references strains are indicated in black bold. Hyphen (-) represents support values $\leq 50 \% / 0.90$. Bold lines represent significant support values from both analyses $(\mathrm{BS} \geq 70 \% / \mathrm{PP} \geq 0.95)$.

Material examined - THAILAND, Krabi Province, Muang City, on dead and twigs of Diospyros malabarica (Ebenaceae), 15 December 2015, C. Phukhamsakda, Kr009 (MFLU 170001, holotype), ex-type living culture, MFLUCC 16-0419, ICMP 21581.

Notes - Magnicamarosporium diospyricola is somewhat similar to $M$. iriomotense in its morphology. Both species occur as saprobic on twigs of dicotyledonous plants. However, $M$. diospyricola differs from $M$. iriomotense in having smaller, thick-walled, rather more hemisphaerical conidiomata, holoblastic to annelidic conidiogenous cells and oblong to pyriform conidia. Whereas $M$. iriomotense differs from the new species by lager conidiomata with cylindrical ostiole, thinner peridium wall, doliiform, holoblastic conidiogenous cells and large and oval conidia (Table. 2). The distinctness of both species is supported in phylogenetic analysis with high supported values. 

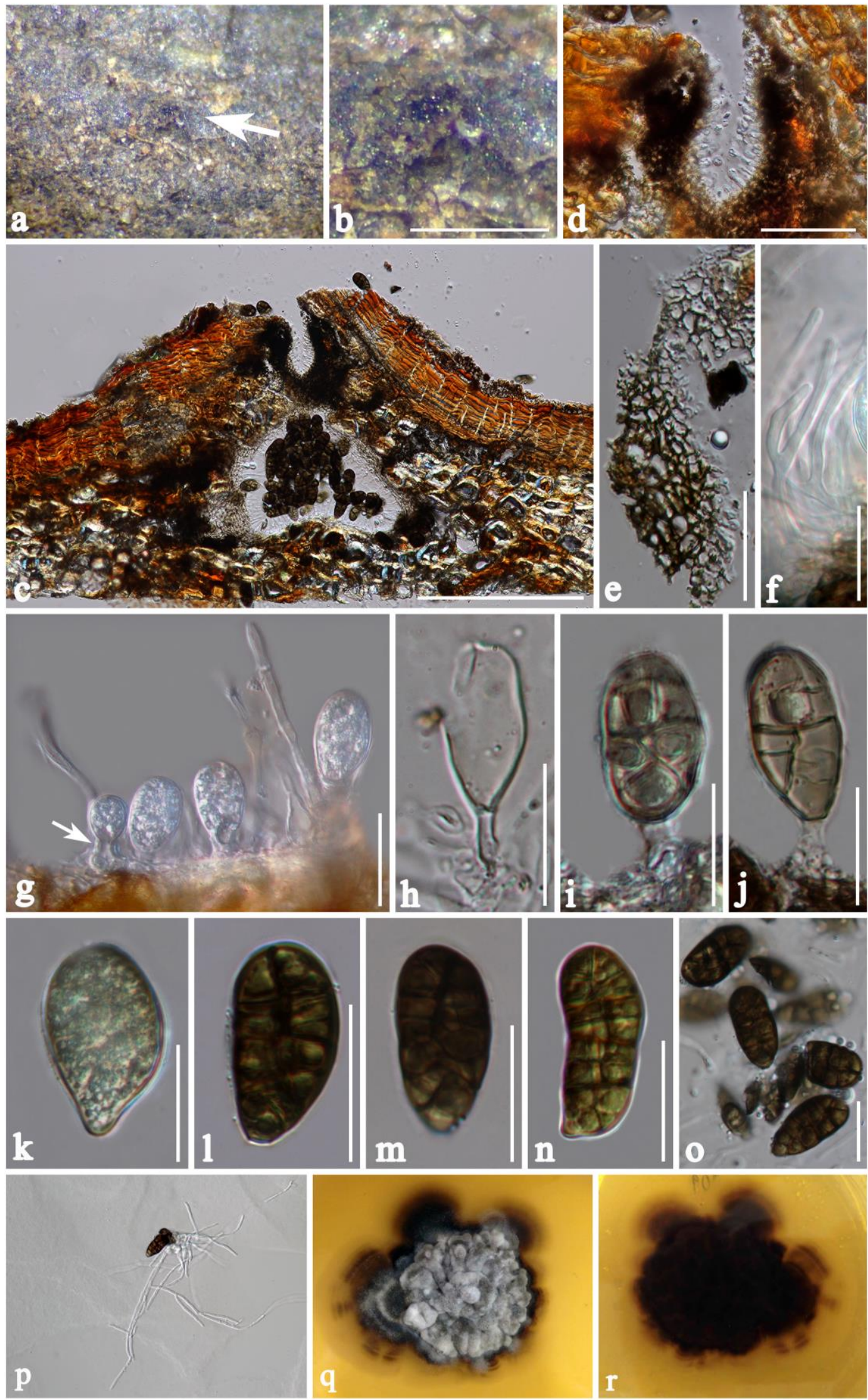

Figure 2 - Magnicamarosporium diospyricola (MFLU 17-0001, holotype). a Appearance of conidiomata on host surface. b Close-up of conidioma on host surface. c Vertical section of conidioma. d Ostiole part. e Pycnidial walls. f Paraphyses. $\mathbf{g}-\mathbf{j}$ Developing stages of conidia from conidiogenous cells. $\mathbf{k}-\mathbf{o}$ Developing stages of conidia. p Germinated conidia. $\mathbf{q}-\mathbf{r}$ Culture characters on MEA. Scale bars: $\mathrm{b}=500 \mu \mathrm{m}, \mathrm{c}=200 \mu \mathrm{m}, \mathrm{d}=100 \mu \mathrm{m}, \mathrm{e}=50 \mu \mathrm{m}, \mathrm{f}-\mathrm{o}=20 \mu \mathrm{m}$. 
Table 2 Synopsis of characters of Magnicamarosporium iriomotense and M. diospyricola.

\begin{tabular}{|c|c|c|}
\hline Name & $\begin{array}{l}\text { M. diospyricola } \\
\text { (This study) }\end{array}$ & $\begin{array}{c}\text { M. iriomotense } \\
\text { (Tanaka et al. 2015) }\end{array}$ \\
\hline Conidiomata & $\begin{array}{l}277-301 \times 289-337 \mu \mathrm{m} \text { under clypeus, } \\
\text { pycnidial, subglobose to depressed globose }\end{array}$ & $\begin{array}{l}330-440 \times 700-760 \mu \mathrm{m}, \text { pycnidial, depressed } \\
\text { globose }\end{array}$ \\
\hline Ostiole & $\begin{array}{l}129-145 \times 74-116 \mu \mathrm{m} \text {, oblong, canal filled with } \\
\text { periphyses }\end{array}$ & $\begin{array}{l}120-150 \times 80-100 \mu \mathrm{m} \text { diam., cylindrical, } \\
\text { papillate, canal filled with periphyses }\end{array}$ \\
\hline Peridium & $\begin{array}{l}10-29 \mu \mathrm{m}(-36 \mu \mathrm{m} \text { at base corner }), 7-9 \text { layers, } \\
\text { brown to dark brown-walled }\end{array}$ & $10-20 \mu \mathrm{m}$ wide, $2-3$ layers, brown-walled \\
\hline Paraph & $29-63 \times 2-4 \mu \mathrm{m}$, regularly $1-2$-septate & $20-50(-80) \times 1.5-2.5 \mu \mathrm{m}$, septate \\
\hline Conidic & Absent & Absent \\
\hline $\begin{array}{l}\text { Conidiogenous } \\
\text { cells }\end{array}$ & $\begin{array}{l}5-10 \times 3-5 \mu \mathrm{m} \text {, integrated, cylindrical. } \\
\text { holoblastic, annellidic, with } 1-2 \text { prominent } \\
\text { annellations }\end{array}$ & $\begin{array}{l}7-11 \times 5-6 \mu \mathrm{m} \text {, holoblastic, cylindrical to } \\
\text { doliiform }\end{array}$ \\
\hline Conidia & $\begin{array}{l}24-35 \times 14-21 \mu \mathrm{m} \text {, with } 5-7 \text { transverse, } \\
\text { obovoid to broad oblong }\end{array}$ & $\begin{array}{l}29-43 \times 24-27 \mu \mathrm{m} \text {, with } 4-6 \text { transverse, oval } \\
\text { to ellipsoid, smooth }\end{array}$ \\
\hline Habitat/Host & Diospyros malabarica (Ebenaceae) & Diplospora dubia (Rubiaceae) \\
\hline
\end{tabular}

\section{Discussion}

Sulcatisporaceae comprises Magnicamarosporium, Neobambusicola and Sulcatispora (Tanaka et al. 2015). The asexual morph of Neobambusicola and Sulcatispora are distinct from Magnicamarosporium. The genus Neobambusicola has erumpent, globose conidiomata and hyaline, smooth, 1-septate, fusoid, lipsoid conidia, with hyaline and aseptate microconidia produced in cultures (Crous et al. 2014). The genus Sulcatispora produces its asexual morph in culture which is characterized by pycnidial, globose conidiomata, annellidic conidiogenous cells and pale-brown to brown, phragmosporous conidia (Tanaka et al. 2015). Whereas Magnicamarosporium has immersed pycnidial conidiomata, holoblastic or annellidic, discrete or integrated conidiogenous cells and muriform conidia.

The genus Magnicamarosporium also shares some characters with Paracamarosporium Wijayaw. \& K.D. Hyde (Didymosphaeriaceae) in having paraphyses among the conidia (Sutton 1980, Nag Raj 1993, Wijayawardene et al. 2014a). However, Magnicamarosporium is unique by its immersed, large-sized, depressed, globose conidiomata and dark-brown conidia. Phylogeny analysis (Fig. 1) shows that Magnicamarosporium resides within the Sulcatisporaceae instead of Didymosphaeriaceae (Tanaka et al. 2015, this study). Our new species Magnicamarosporium diospyricola, found on twigs Diospyros malabarica is placed in Sulcatisporaceae with other strains of Magnicamarosporium, but as a distinct species.

\section{Acknowledgement}

Chayanard Phukhamsakda would like to thank the Royal Golden Jubilee PhD Program under Thailand Research Fund, for the award of a scholarship no. PHD/0020/2557 to study towards a PhD. We thank the Plant Germplasm and Genomics Center in Germplasm Bank of Wild Species, Kunming Institute of Botany for help with the molecular work.

\section{References}

Assembling the Fungal Tree of Life (AFTOL) website - http://www.aftol.org. (Accessed 20 November 2016).

Benson DA, Cavanaugh M, Clark K, Karsch-Mizrachi I et al. 2013 - GenBank. Nucleic acids research. 41: D36-D42.

Carbone I, Kohn LM. 1999 - A method for designing primer sets for speciation studies in filamentous ascomycetes. Mycologia 91: 553-556.

Chomnunti P, Hongsanan S, Hudson BA, Tian Q et al. 2014 - The Sooty Moulds. Fungal Diversity $66,1-36$. 
Crous PW, Slippers B, Wingfield MJ, Rheeder J et al. 2006 - Phylogenetic lineages in the Botryosphaeriaceae. Studies in Mycology 55, 235-253.

Crous PW, Wingfield MJ, Schumacher RK, Summerell BA et al. 2014 - Fungal Planet Description Sheets: 281-319. Persoonia 33, 212-289.

Guindon S, Dufayard JF, Lefort V, Anisimova M et al. 2010 - New algorithms and methods to estimate maximum-likelihood phylogenies: assessing the performance of PhyML 3.0. Systematic biology 59, 307-321.

Huelsenbeck JP, Ronquist F. 2001 - MRBAYES: Bayesian inference of phylogenetic trees. Bioinformatics 17, 754-755.

Index Fungorum 2016 - http://www.indexfungorum.org/Names/Names.asp. (Accessed 3 December 2016).

Jayasiri SC, Hyde KD, Ariyawansa HA, Bhat DJ et al. 2015 - The Faces of Fungi database: Fungal names linked with morphology, phylogeny and human impacts. Fungal Diversity 74, 3-18.

Katoh K, Standley DM. 2013 - MAFFT multiple sequence alignment software version 7: improvements in performance and usability. Molecular Biology and Evolution 30, 772-780.

Liu JK, Hyde KD, Jones EG, Ariyawansa HA et al. 2015 - Fungal diversity notes 1-110: taxonomic and phylogenetic contributions to fungal species. Fungal Diversity 72, 1-97.

Miller MA, Pfeiffer W, Schwartz T. 2010 - Creating the CIPRES Science Gateway for inference of large phylogenetic trees. In Proceedings of the Gateway Computing Environments Workshop (GCE), New Orleans, LA pp. 1-8.

Nag Raj TR. 1993 - Coelomycetous anamorphs with appendage-bearing conidia. Mycologue publications: Waterloo, Southern Ontario, Canada.

Nylander JAA. 2004 - MrModeltest 2.0. Program distributed by the author. Evolutionary Biology Centre, Uppsala University.

O'Meara BC, Ane C, Sanderson MJ, Wainwright PC. 2006 - Testing for different rates of continuous trait evolution using likelihood. Evolution 60: 922-933.

Phukhamsakda C, Ariyawansa HA, Phookamsak R, Chomnunti P et al. 2015 - Muriphaeosphaeria galatellae gen. et sp. nov. in Phaeosphaeriaceae (Pleosporales). Phytotaxa 227: 55-65.

Piel WH, Donoghue MJ, Sanderson MJ. 1999. - TreeBASE: a database of phylogenetic information. Abstracts of the XVI International Botanical Congress, St. Louis.

Rambaut A, Drummond A. 2008 - FigTree: Tree figure drawing tool, version 1.2. 2. Institute of Evolutionary Biology, University of Edinburgh.

Rambaut A, Suchard MA, Xie D, Drummond AJ. 2014 - Tracer version 1.6, Available from http://beast.bio.ed.ac.uk/Tracer.

Rannala B, Yang Z. 1996 - Probability distribution of molecular evolutionary trees: a new method of phylogenetic inference. Journal of Molecular Evolution 43, 304-311.

Saccardo PA. 1883 - Sylloge Pyrenomycetum, Vol. II. Sylloge Fungorum 2, 1-813.

Schulzer S. 1870 - Mykologische Beiträge. Verhandlungen der Zoologisch-Botanischen Gesellschaft Wien 20, 635-658.

Silvestro D, Michalak I. 2011 - raxmlGUI: a graphical front-end for RAxML. Organisms Diversity \& Evolution 12, 335-337.

Stamatakis A, Hoover P, Rougemont J. 2008 - A rapid bootstrap algorithm for the raxml web servers. Systematic Biology 57, 758-771.

Sutton BC. 1980 - The Coelomycetes. Fungi imperfecti with pycnidia, acervuli and stromata, In: 123-128. Commonwealth Mycological Institute, Kew, Surrey, UK.

Tamura K, Stecher G, Peterson D, Filipski A, Kumar S. 2013 - MEGA6: molecular evolutionary genetics analysis version 6.0. Molecular Biology and Evolution 30, 2725-2729.

Tanaka K, Hirayama K, Yonezawa H, Sato G et al. 2015 - Revision of the Massarineae (Pleosporales, Dothideomycetes). Studies in Mycology 82, 75-136.

Wijayawardene NN, Crous PW, Kirk PM, Hawksworth DL et al. 2014a - Naming and outline of Dothideomycetes 2014 including proposals for the protection or suppression of generic names. Fungal Diversity 69, 1-55. 
Wijayawardene NN, Hyde KD, Bhat DJ, Camporesi E et al. 2014b - Camarosporium-like species are polyphyletic in Pleosporales; introducing Paracamarosporium and Pseudocamarosporium gen. nov. in Montagnulaceae. Cryptogamie Mycologie 35, 177-198.

Wijayawardene NN, Hyde KD, Wanasinghe DN, Papizadeh M et al. 2016 - Taxonomy and phylogeny of dematiaceous coelomycetes. Fungal Diversity 77, 1-316.

Zhaxybayeva O, Gogarten JP. 2002 - Bootstrap, Bayesian probability and maximum likelihood mapping: exploring new tools for comparative genome analyses. BMC genomics 3, 1-4. 